become "non-visiting" doctors and to have waiting lists of up to a week before a National Health Service patient can see them ? We all know these circumstances do exist, but these doctors do not do private practice.

I would be pleased to hear the views of other doctors practising from Crown property health centres, and also to know what would happen if every health centre GP refused to sign this health centre licence.

G M COLEMAN

Birmingham 17

\section{Academy of medicine}

SIR,-Does Britain need an academy of medicine ? This question was posed in a recent leading article (22-29 December, p 1611) and it must be answered.

As someone who has spent his entire working life in the NHS, it is with anger, frustration, and regret that over the years I have witnessed the exclusive, narrow, often conflicting interests of such bodies as the universities and medical schools, the BMA, the GMC, and the royal colleges producing an impression of sectional self-interest. I am assuming it is the general desire and intention of both the general public and the medical profession for the NHS to survive and succeed; and, of course, I accept that such an egalitarian concept will produce conflicts of interests and values. But, particularly at a time of increasing financial difficulties, it is more important than ever that the medical profession provides strong leadership so that present and future policies can be discussed and formulated in an atmosphere of informed debate.

Such leadership could come about through the formation of an academy or institute of medicine. It must be professionally and politically independent but able to study and correlate information and advice which is available from the multiplicity of medical organisations already present in this country. Probably, like the Institute of Medicine within the US National Academy of Sciences, its membership should be small and appointed for a limited period of time. There is no need for a prestigious headquarters and a consequent bureaucracy. How it should be established and funded is, of course, crucial; but perhaps the Board of Health in Denmark has given a lead and our own Parliament could set up a central advisory agency (British Academy of Medicine) which is totally independent of any government, but which must be consulted before Parliament can recommend any changes in health policies.

Let us hope therefore that medicine in this country is capable of accepting-and determined to accept-this leadership. It is constantly being said that British medicine is in danger of losing its pre-eminence in the world. Let us show that pre-eminence is concerned not only with biomedical research and technology, with the Medical Research Council and Nobel prize winners, but equally with influencing and initiating similar advances in the organisation and provision of health care.

Health care is a product of the social and political environment of any country and I believe that the vast majority of the British people are wholeheartedly supportive of the original concepts of the NHS. If British medicine, through an academy or institute, can show that it is likewise fully committed to the fair distribution of available resources so that priority may be judged on medical need alone and fortuitous privilege abolished, and if it can educate both politicians and the general public about what is possible and realistic within a limited budget, then it will again lead the world.

Wells, Somerset

JOHN STEPHEN

\section{Health visitors and confidentiality}

SIR,-In your issue of the 15 December (p 1591) Miss Margaret Rushforth of the Health Visitors Association writes about her members' concern about a Guardian report that health visitors are feeding information from general practitioners' records into computers without the consent of the doctors. As Warwickshire is specifically mentioned I would be grateful for the opportunity to clarify my committee's position.

My committee has no reason to believe that Warwickshire health visitors are feeding information from general practitioners' medical records into computers without the doctors' consent. My committee is, however, very concerned about the way in which some clinical information is being collected in Warwickshire without the patients' being aware of its destination. At an antenatal clinic a patient normally supplies information about previous pregnancies in order that the obstetric team may use the knowledge in the interest of her own care and that of her child in the perinatal phase. In Warwickshire such information is now being entered on the child's community health record without the mother's necessarily being aware of the fact and certainly without her written consent. Later the health visitor enters additional sensitive information on the same records, again without having to obtain the patient's permission. The additional information includes the father's occupation and the family's ethnic group.

In my committee's opinion Warwickshire Area Health Authority's actions are in conflict with the BMA's policy as determined by the Representative Body in 1977-that is, "That in all medical records, information should be regarded as held for the specific purpose of the continuing care of the patient and should not be used, without the appropriate authorisation by the responsible clinician or consent of the patient, for any other purpose."

My committee has reason to believe that some Warwickshire health visitors are unhappy about the AHA's policy and are in agreement with the BMA's resolution. Finally, I am happy to say that to the best of our knowledge and belief relationships in Warwickshire between health visitors and general practitioners are mostly excellent.

\section{B D M Williams} Honorary Secretary, Warwickshire Warwick

\section{Multidisciplinary teams}

SIR,-Drs James Appleyard and J G Maden (17 November, $p$ 1305), discuss some of the problems of multidisciplinary teams. There seems to be some confusion in this article about the role and function of the educational psychologist, which one would wish to clarify. One confusion concerns decisions on the special education of disturbed children. Such decisions are, of course, the responsibility of the director of education for the area in which a child resides, usually in consideration of the reports provided on forms SE14, completed by the child's present school, a clinical medical officer of the AHA, and an educational psychologist of the local education authority concerned. These forms are often accompanied by additional reports from those who complete them, and sometimes from social workers, psychiatrists, clinical psychologists, or other medical or paramedical personnel who may be concerned with a particular child. However, these people are responsible not for making decisions, only for making recommendations.

The suggestion that principal educational psychologists, whether or not holding joint appointments as assistant education officers or advisers for special education, make recommendations which are not in the child's interest but in the interest of their employing education authority is directly counter to the codes of professional conduct which govern their actions; it could equally be argued that principal educational psychologists are more relevantly qualified to advise on educational matters than is a doctor whose expertise is not educational-just as it is suggested subsequently the management, medication, and treatment of a hospital patient is the particular responsibility of the doctor.

Whatever the reservations one may have about interdisciplinary teams in their present formations, there would seem to be little advantage in their members' making inaccurate and contentious statements about other disciplines if there is to be the general goodwill to make such arrangements work in the interest of the children and adults whose interests they should attempt to serve.

Lea Pearson Chairman, Division of Educational and Child Psychology,
British Psychological Society

Leicester LE1 7DR

Participation in national quality control schemes

SIR,-A survey has shown that almost all laboratories directly supervised by consultants (or equivalent) take part in the main national quality control schemes for clinical chemistry, haematology, and microbiology. However, it is apparent that a number of small laboratories that are working alongside larger laboratories (both covered by the same head of department) are not direct participants. They may well have quality control referred to the results of the parent laboratory.

The Joint Working Group believes that this procedure may not provide a sufficiently rigorous check. We urge all heads of departments to arrange for their smaller or satellite laboratories to take an independent part in the national schemes-the results to be returned to the appropriate head of department.

D N BARON Chairman, Joint Working Group
on Quality Control Royal Free Hospital, 